\title{
Tarımda Mikorizal Fungusların Etkinliği
}

\author{
Nurhan ÖZTÜRK ${ }^{1}$ Esin BASIM² Hüseyin BASIM ${ }^{3}$ \\ ${ }^{1}$ Akdeniz Üniversitesi, Korkuteli MYO, Mantarcılık Programı, Antalya \\ ${ }^{2}$ Akdeniz Üniversitesi, Korkuteli MYO, Bahçe Tarımı Programı, Antalya \\ ${ }^{3}$ Akdeniz Üniversitesi, Ziraat Fakültesi, Bitki Koruma Bölümü, Antalya
}

\begin{abstract}
Öz: Mikoriza, oluşturduğu misel yapıları ile birçok bitkinin kökleri arasındaki etkileşim sonucunda her iki organizmanın da karşılıklı yararlanmasına dayanan bir ilişki oluşturmaktadır. Bu ilişkide mikorizal fungus, gelişimi için bitkiden karbon ve esansiyel organik maddeleri temin ederken, bitkinin de su ile besin elementleri, tuz ve metabolitleri alınmasına yardımcı olmaktadır. Böylece, bu etkileşimde her iki taraf da yarar sağlamaktadır. Tarımda değişik alanlarda kullanılan mikorizal gruplardan en önemlileri endomikoriza ve ektomikorizalardır. Mikorizal funguslar ve bitki kökleri arasındaki bu simbiyotik ilişki, doğadaki ekolojik dengenin anlaşılmasına büyük katkılar sağlayan ototrof konukçu ile heterotrof organizma arasındaki besin alışverişini ortaya koyan en güzel örneklerden birisidir. Günümüze çok sayıda bitkinin funguslarla simbiyotik bir ortaklık oluşturduğu çeşitli çalışmalarla tespit edilmiştir. Bu derlemede, mikoriza kullanımının tarımın birçok alanında özellikle toprak ıslahı ve verimliliği, bitki gelişimi, bitki hastalıkları üzerine olan etkileri ve önemi hakkında bilgi verilmiştir.
\end{abstract}

Anahtar kelimeler: Mikoriza, Mikorizal Fungus, Endomikoriza, Ekzomikoriza.

\section{Effectiveness of Mycorrhizal Fungi in Agriculture}

\begin{abstract}
Mycorrhizal fungus forms a mutual benefit as a result of interactions between many plant roots and mycelium structures. While mycorrhizal fungus in this relationship provides essential carbon and organic matter from plants, it also helps to plant uptaking water, nutrients, salt and metabolites. Thus, the both sides in this interaction provide benefit from each other. The important mycorrhizal groups used in various areas of agriculture are endomycorrhizae and ectomycorrhizae. Mycorrhizal fungi and their symbiotic relationships with plant roots is one of the most important example of demonstrating the nutrient exchange between host and heterotrophic organisms feeding patterns that contributes significally to our understanding of the ecological balance in the nature. Nowadays, a large number of effective detection of mycorrhizal fungi that form a symbiotic partnership with the plant has been identified by many studies. This reviewed will be focused on the importance of mycorrhizal fungi use in many areas of agriculture, especially the effects on plant development, plant diseases, the soil fertility and improvement.
\end{abstract}

Key words: Mycorrhizae, Mycorrhizal Fungi, Endomycorrhizae, Ectomycorrhizae. 


\section{Giriş}

Mikorizal fungusların yeryüzünde oluşumunun çok eski dönemlere dayandığı tahmin edilmekte ve mikorizal fungusların, bitkiler ile simbiyotik ilişki kurarak bitkilerin yeryüzüne yayılışında önemli rol oynadıkları düşünülmektedir (Smith ve Read, 2008). Mikoriza terimi Yunanca'da myces (Fungus), rhiza (kök) anlamına gelen sözcüklerin bir araya gelmesiyle oluşmuştur. İlk kez 1885 yılında Frank tarafından bazı bitkilerin köklerinde yoğun bir şekilde kolonize olan, fakat hastalık oluşturmayan funguslar saptanmış ve bitki kökleriyle bazı fungusların ortak yaşamlarını tanımlamada kullanılmıştır(Moser ve Haselwandter, 1975; Hayman, 1981). Bitkiler ile mikroorganizmalar arasında görülen mikorizal ortak yaşam biçimi, bilinen diğer simbiyotik yaşam biçimleri arasında en yaygın ve en önemli olanıdır (Allen, 1991). Son yıllarda, mikorizal ortak yaşam önem kazanmaya başlamış ve bu alanda yapılan çalışma sayısı da giderek artmıştır (Gai vd., 2006; Martin ve Slater, 2007).

Mikorizal funguslar ve bitki kökleri arasındaki ortak yaşam ilişkisinde, heterotrof organizma ile ototrof konukçu arasındaki besin alışverişindeki önemli kısım, farklı cinslere ait mikorizal fungus türlerinin birçok farklı familyadaki bitki türlerine özelleşebildikleridir (Smith ve Read, 2008).

Mikorizal fungusların miselleri ile bitki kökleri arasında oluşan bağlantı sonucunda bir dizi etkileşim gerçekleşmektedir. Bu etkileşim doğrultusunda bitki köklerinden kök salgıları toprakta bulunan mikorizal funguslara ait sporların çimlenmesi ile hif tüpünün oluşması sonucu hifler bitki köklerine yönelmektedir. Böylece kök ile hifler arasında bağlantı gerçekleşmiş olmaktadır. Bu temastan sonra kök ile hif arasında gerçekleşen güçlü bir adhezyon vasıtasıyla kök yüzeyine bağlanan mikorizal funguslar, aprosoryum oluşturarak bitki kökünü penetre etmekte ve kök dokusunda intersellüler olarak yayılış göstermektedirler (Peterson ve Farquhar, 1994). Kök yüzeyinde oluşan yoğun fungal örtü ve misel yapısı bitki kökünün ulaşamadığı yerlere ulaşarak bitkiye yarar sağlamaktadır. Bu yarar sonucunda, fungus bitkiden karbon alırken, bitkinin sağladığı kazanç mikorizal fungusların topraktan aldığı besin maddeleri ve suyun bünyesine ulaştırılmasıdır (Erzurumlu ve Kara, 2014).

Mikorizal funguslar; spor yapısına, bitkilerde oluşturduğu etki şekillerine ve kök içinde morfolojik ve fizyolojik yapılarına göre büyük farklılıklar gösterdikleri için farklı şekilde gruplandırılmaktadırlar. Mikorizal fungusların oluşturduğu miselin kök yapısı ile ilişkisine göre endomikorizalar ve ektomikorizalar olmak üzere iki büyük grup oluşturmaktadırlar. Genel olarak orman ağaçları ile bazı meyve ağaçlarında ektomikoriza tipi bir ortak yaşam görülürken, çoğu kültür bitkilerinde ve bazı meyve ağaçlarında ise endomikoriza tipi ortak yaşam görülmektedir (Marschner, 1995). Ayrıca, bu iki büyük grup dışında ericaceous ve orkide mikoriza grupları da bulunmaktadır.

Ancak, tarım açısından kullanılan endomikorizalar ve ektomikorizalar daha geniş alanda kullanılmaktadırlar (Anonim, 2014).

Doğal ekosistemdeki bu yararlı ortak yaşam, bitki köklerinin bir parçası olan mikorizal fungusların topraktaki yararlı mikroorganizmalarla etkileşime girmesi sonucu bitkide kök eksüdasyonu çoğalmakta ve kuru madde üretimi \%25 oranında artmaktadır. Bu etkileşim sonucunda mikorizal funguslar, bitki büyümesini arttırarak bitki canlılığının korumasında rol alan etkili faktörlerden birisi olarak görülmektedir (Sharma vd., 1992). Mikorizal fungusların, bitki gelişimi üzerine etkileri şunlardır:

- Bitki besin elementlerini ve su alımını arttırarak bitki gelişimini arttırırlar,

- Kimyasal gübre kullanımını azaltarak çevreye yarar sağlamaktadırlar,

- Fumigasyon veya solarizasyon sonrası yapılan ekim sonrası oluşan bitkilerin bodur kalmasını önleyerek bitki ekim kalitesini arttııırlar ve erken bitki çıkışını sağlarlar, 
- Şaşırtma sırasındaki fide şokunu ve fide kayıplarını azaltırlar,

- Patojenlerin etkilerine karşı bitkiyi korurlar,

- Zayıf gelişen fide sorunlarını azaltırlar,

- Kuraklık ve çevre koşullarına karşı oluşan streslere karşı bitkiyi korurlar ve gelişim direncini arttırırlar,

- Kirletilmiş ve hatalı tarım uygulamaları sonucu zarar görmüş topraklardaki olumsuz etkileri de azaltmaktadırlar (Ortaş, 1998).

Kök ile birlikte simbiyotik olarak yaşayan mikoriza türlerinin birçok yararı olduğu gibi tarımsal üretimdeki kullanım alanı da her geçen gün hızla artmaktadır.

\subsection{Ektomikorizalar}

Genel olarak orman ağaçları ve bazı meyve ağaçları ile ortak yaşam oluşturan ektomikorizalar, oluşturdukları farklı yapıları ile karakterize edilmektedirler. Bu yapılardan birisi fungal örtüdür (mantle). Fungal örtü bitkilerde kökün dış yüzeyindeki kökçük yapısında çok sayıda dallanmış olan hif örtüsü ile karakterize edilen bir yapıdır. Bu örtünün kalınlığı ve yapısı ortak yaşam gösteren türe ve yetiştiği çevresel koşulları bağlı olarak yüksek oranda farklılık göstermektedir. Ortak yaşam oluşturan fungus için bu fungal örtü oluşumu, besin maddesi ve karbon deposu olarak görev yapmaktadır. Bir diğer karakteristik yapı ise harting net' tir. Bu yapı, kökün daha dış kısımlarındaki kortekste kortikal ve epidermal hücreler arasında hücre içi intraselluler hiflerin yoğun yığınlar halinde bir araya gelmesinden oluşmaktadır. Konukçu bitki ve fungus arasındaki karbonhidratlarla minerallerin değiş tokuş edildiği yapı harting net ile gerçekleşmektedir. Bir diğer karakteristik yapı ise external miselyum olan dış fungal örtüden toprak içine yayılış gösteren hiflerden oluşan misel yapısıdır. Bu misel besin alımı, besin maddelerinin hareketini, su alımını ve topraktaki diğer yararlı mikroorganizmalar ile etkileşim oluşturabilmeleri için geniş bir yüzey alanı oluşturmasından dolayı oldukça önemlidir (Şekil 1) (Kibar ve Pekşen, 2007).

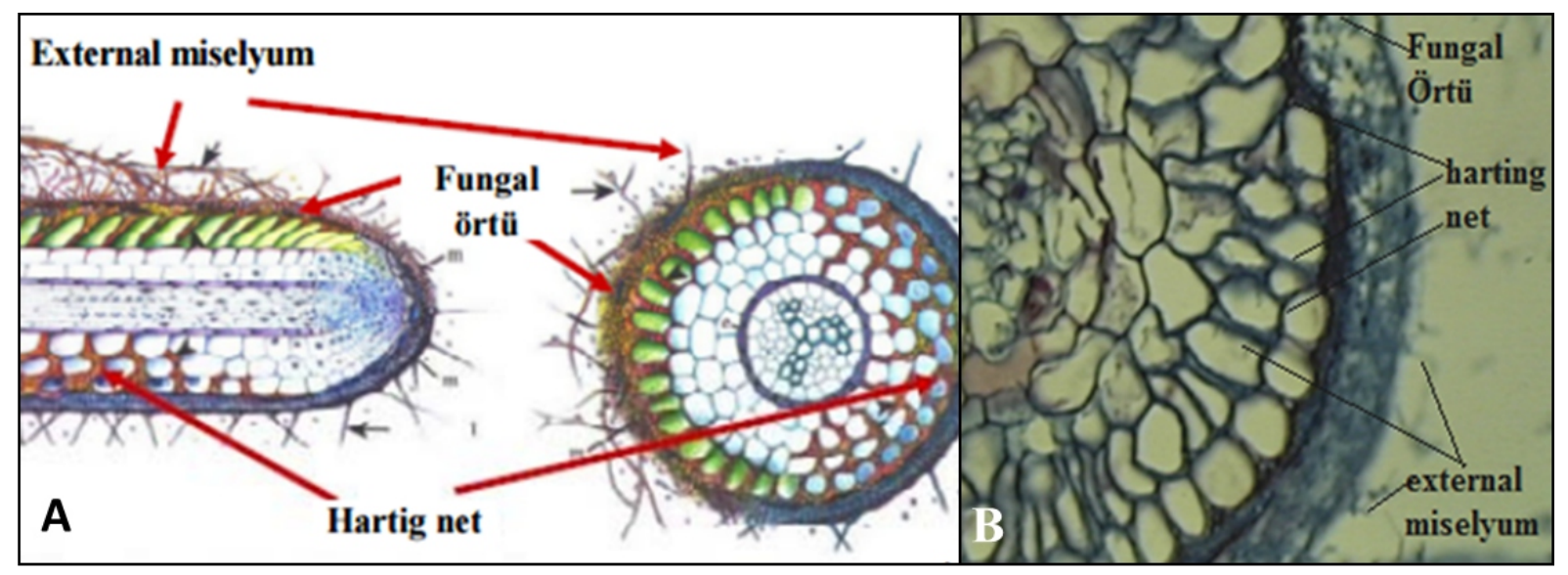

Şekil 1. Ektomikorizaların bitki kökleri ve dokularında oluşturduğu yapılar (A: Peterson vd., 2004; B: Plantscience 4u, 2016) 
Ektomikorizal funguslar, tarımda önemli yer tutan fungus gruplarından birisini oluştururlar. Ektomikorizal fungus gruplarının çoğunluğunu Basidiomycota bölümü oluştururken toplamda 65 cins mevcuttur. Bu grupta 45' i Basidiomycota, 18' i Ascomycota ve geri kalanı da Zygomycota bölümüne aittir. Örneğin; Basidiomycota'dan Agaricales takımından Boletus, Amanita, Tricholoma ve Suillus cinsleri, Russulales takımından Lactarius, Cortinarius ve Russula cinsleri, Aphyllophorales takımından Thelephora cinsi, Hymenogastrales takımından Rhizopogon cinsi ve Sclerodermatales takımından Scleroderma cinsi, Ascomycota bölümünden Tuberales takımından Tuber cinsleri ve Zygomycota'dan Endogonales takımına giren cinsler ektomikorizal ortak yaşam gösteren funguslardır (Isaac, 1992; Anonymous, 2007).

Ektomikorizal funguslar tropik alanlardan çok mevsimsel iklim değişikliklerinin olduğu ılıman alanlarda çok daha yaygın simbiyoz oluşturmaktadırlar (Carlile ve Watkinson, 1995). Dünya florasının yaklaşık \%10'nunda ektomikorizal funguslar başlıca Fagaceae (meşe, kestane, kayın), Pinaceae (çam, göknar, karaçam, ladin baldıran), Juglandaceae (Amerikan cevizi, pekan), Betulaceae (kızılağaç, huş) Salicaceae (kavak, söğüt), Myrotaceae (okaliptüs) ve diğer bazı ağaçlarda ortak yaşam oluşturmaktadırlar (Marx, 2001). Ektomikorizal fungusların ortak yaşamdaki etkinliği üzerine yapılan araştırmalarda en çok kullanılan ağaç türleri çam (Pinus) ve kayın (Fagus)'dır (Carlile ve Watkinson, 1995).

Ektomikorizal funguslar ile bitki etkileşime girdiğinde oluşan kolonizasyon emici köklerde şekil ve renk değişikliklerine neden olur. Köklerin şekilleri çatallı, çok dallanmış olabilirken, rengi kırmızı, sarı, siyah, beyaz, kahverengi veya karışık renklerde olabilir (Marx, 2001). Birçok ektomikorizal fungus, bitki kılcal köklerinin dallanmasını artıran bitki büyümesini geliştirici gibberellin, oksin, etilen ve sitokinin gibi bitki büyüme düzenleyici hormonları üretirler. Bu nedenle, kök yapısının absorptif kapasitesinin artması ile kök ve fungus dokusu arasındaki temas yüzeyi artmış olur. Bu dallanma biçimi ile bitki kökü etrafında mantar dokunun oluşturduğu manto yapısı ektomikorizaları karakterize ederek topraktaki miselden sağlanan besinler için bir depo olarak görev yapmaktadır. Aynı zamanda bazı patojenlerden ve olumsuz çevre koşullarından kılcal bitki köklerini korumaktadır (Şekil 2) (Molina vd., 1993; Molina vd., 2001).

Dünyada ektomikorizal funguslar ile yapılan çalışmalarda ektomikorizal fungusların bitki gelişimini olumlu etkilediği ve besin maddesi alımını artırdığı saptanmıştır (Akitsu vd., 2000; Souza vd., 2004; Turjaman vd., 2006; Repac, 2007). Ülkemizde özellikle orman ağaçlarında bulunan ektomikorizalarla ilgili yok denecek kadar az çalışma olmasına rağmen, ektomikorizal fungusların önemi bazı çalışmalar ile vurgulanmıştır (Kara, 2000; Kara ve Tilki, 2001; Tilki ve Kara, 2004; Kibar ve Pekşen, 2007, 2011; Pekşen ve Kibar, 2007; Tüfekçi, 2007; Toprak vd., 2014, Toprak vd., 2016)

\subsection{Endomikorizalar}

Endomikorizal grubu oluşturan funguslar, Fungi aleminin içinde yer alan Glomeromycota bölümü üyeleridir. İpliksi misel topluluklarına sahip olmasıyla arbusküler (çalı-benzeri) olarak adlandırılan genel cinse Glomus adı verilmiştir (Holt, 2009). Glomeromycota bölümü funguslar 600 ile 620 milyon yıl önceden oluşmuş olan çok eski bir gruptur. (Amaranthus, 2004; Redecker, 2008).

Endomikorizal funguslar üzerinde en çok araştırma yapılan ve kullanılan mikorizalardır. Arbusküler mikorizal funguslar taksonomik olarak Zygomycetes sınıfı, Glomerales takımı, Glomeraceae familyasına bağlı olup, Entrophospora spp., Acaulospora spp., Glomus spp., Syclerocystis spp. Scutellospora spp. ve Gigaspora spp. türlerini kapsarlar. Arbusküler mikorizal fungusların etkisi ilk olarak 1959 yılında rapor edilmiştir (Baylis, 1959). 

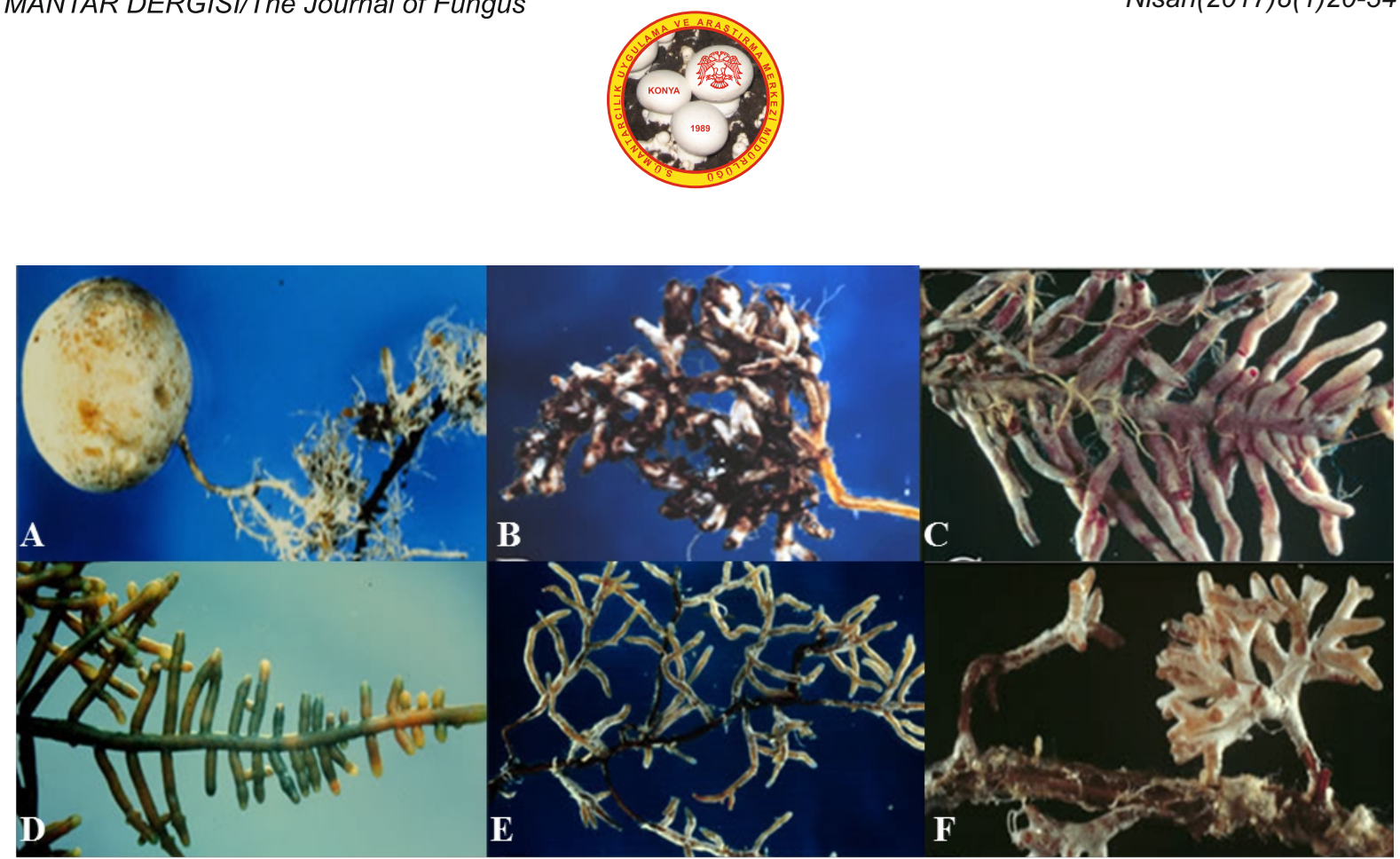

Şekil 2. Farklı ektomikorizal kökler; A, Hysterangium sp. (Tuberales)

$\mathrm{B}$, Rhizopogon vinicolor (Boletales) C, Poria terrestris (Polyporales);

D, Lactarius sanguifluus (Russulales); E-F, Amanita muscaria (Agaricales)

(Mycorrhizal Associations, 2008).

Endomikorizaların karakteristik yapısı; hem kortekste hücre içi boşluklarda hem de hücreler arası boşluklarda meydana gelmektedir (Sieverding, 1991; Harley ve Smith, 1983; Smith ve Read, 1997). Endomikorizal funguslar, hücre içinde ağaçların kök tipi gibi dallanmaya benzeyen arbüskül olarak adlandırılan yapılar (Şekil 3-A) oluşturmaktadır. Endomikorizal funguslar kortekste geliştiği için ortamda lipitçe zengin oval şekilli olan vesikül (Şekil 3-B) adı verilen yapıları oluşturmaktadırlar (Marschner, 1995; Mossea, 1981). Arbusküler mikorizalar, hiflerini toprak içine salarlar ve oluşan misel ağı çift yönlü besin maddesi hareketini teşvik ederek toprak besinlerinin ve suyun bitkiye yönelmesini ve bitkide oluşan fotosentez ürünlerinin misele geçmesini sağlarlar. Arbusküler mikorizal funguslar; hifler, ekstraradikal ve intraradikal sporlar, vesikül intraselluler depo yapıları ve ekstra radikal hiften dallanan yardımcı hücreler ile bitki köklerinin kabuk hücreleri etrafında ve hücreler içinde misel ağı oluştururlar (Dalpe ve Monreal, 2004). Bu yapılarla, bitki kökleri ve mikorizal fungus arasında etkileşim ile ortak yaşam başlamaktadır.
Endomikorizaların bitkiler ile etkileşimlerinin sonucu, çoğunlukla kök yüzeyinde oluşan ekstraradikal misellerin penetrasyonundan 3-4 hafta sonra dinlenme sporları olan klamidosporlar oluşmaktadır. Bazı türlerde dinlenme sporunun oluşumu 6 aya kadar uzayabilmektedir. Klamidosporların büyüklükleri mikorizal türlere göre farklılık göstermekte boyutları 15$800 \mu \mathrm{m}$ arasında olmaktadır. Mikorizal funguslar, bu sporlar sayesinde canlılığını toprakta birkaç yıl koruyabilmektedir (Sieverding, 1991) (Şekil 3-C).

Tarımda en çok kullanılan endomikorizal grubu olan arbusküler mikorizalar; bitki gelişimini, özellikle de bitki besin maddelerinin miktarlarının kritik seviyelerinde olan topraklarda ve zor çevre koşullarında besin elementi alımını teşvik etmekte ve kök gelişimini, köklerin absorbsiyon gücünün artması sonucunda da besin maddesi ve su alınımını, köklerdeki hücre yenilenmesini olumlu yönde etkilemektedirler (Sieverding, 1991; Ortaş, 2002). 


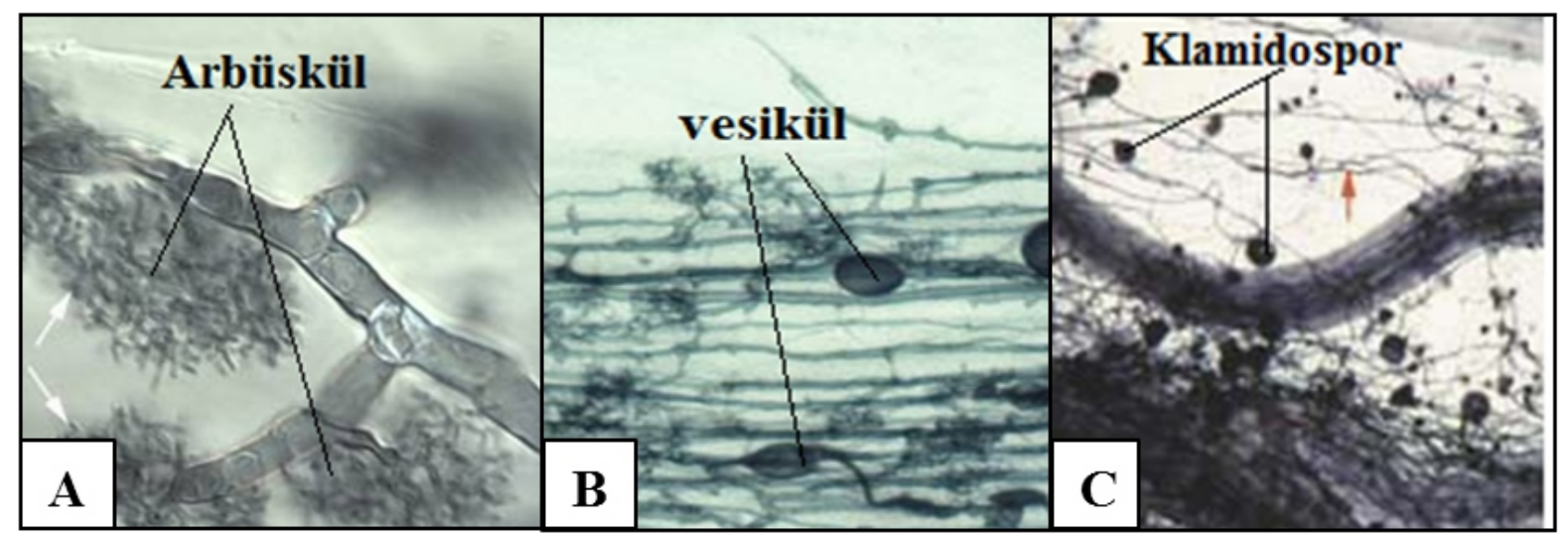

Şekil 3. Endomikorizaların bitki dokusunda oluşturduğu yapılar. A: Arbüskül yapısı; B: Vesikül yapısı C: Klamidospor (www.mycorrhizas.info).

\subsection{Tarımda Mikorizaların Etkinliği}

Ülkemizde mikorizal funguslarla ilgili yapılan çalışmalarda hem mikoriza çeşitleri hem de bu mikoriza çeşitlerinin otsu ve odunsu bitkilerin dışında meyve ve sebzelerde uygulanmasına yönelik çalışmalarda mikorizaların olumlu yönde etki gösterdiği belirlenmiştir. Mikorizaların bitki büyümesinde ve bitkinin ürün veriminde etkili bir faktör olmasının yanında bitkilerdeki hastalık ve zararlılara karşı da bitkinin direncini arttırdığı çeşitli çalışmalarla ortaya konulmuştur. Ülkemizde ise mikorizal fungusların etkinliği ile ilgili çalışmalar yeni olup, son dönemlerde bu alanda gittikçe artan oranda araştırma çalışmaları oluşturularak, elde edilen etkili mikorizal fungus türlerinin tarımda kullanılabilirliği sağlanmaktadır.

\subsubsection{Mikorizal Fungusların Bitki Gelişimine Etkinliği}

Mikorizalar, bitkinin yarar sağlayamadığı çözünürlük oranı az olan besin elementlerini, özellikle de fosforu absorbe ederek bitkiye gerekli olan diğer besin elementini aktarmaktadırlar. Yetiştiriciliği yapılan bitkilerin, toprak fungal hastalık etmenlerine ve topraktaki nematodlara karşı bitkinin dayanıklılığını arttırmaktadırlar. Daha iyi beslenerek gelişen mikorizalı bir bitkinin, herhangi bir uygulama yapılmadan gelişen mikorizasız bitkiye oranla obligat bitki patojenlerine karşı daha dayanıklı olduğu gözlenmiştir (Demir ve Onoğur, 1999).

Mikorizalar, bitki köklerini çevre faktörlerinin neden olduğu ağır metal toksisitesi ve tuzluluğa karşı bitkiyi koruyarak bitkinin direncini artırmaktadırlar (Harley ve Smith, 1983). Ayrıca mikorizal funguslar, verimsiz toprakların bitki büyümesi üzerindeki olumsuz etkilerini de azaltabilmektedirler (Mossea, 1981). Mikorizal funguslar, bitki patojenlerine karşı da bitkinin direncini artırarak bitkiyi beslerler ve direkt rizosferde zararlı organizmalarla mücadele ederek etkinliği arttırırlar (Dehne ve Schanbeck, 1979).

Mikorizal etki, olumsuz çevre koşullarının başında gelen kuraklık koşullarına karşı bitki dayanıklıığını da artırabilmektedir. Bu etki, direkt hifler ile olabildiği gibi mikorizanın bitki fizyolojisi ve morfolojisi üzerinde yaptığı farklılaşmadan dolayı kılcal kök oluşumu ile de etkili olmaktadır (Davies vd., 1992).

Mikorizal funguslar, toprakta fazla fosfor olduğu zaman inaktif duruma geçmekte ve bu etki sonucunda diğer bazı bitki besin elementlerinin alınamamasına neden olmaktadır (Menge vd., 1978; Graham, vd., 1981; Robson, vd., 1993). 
Mikorizaların, fosfor içeriği düşük olan verimsiz topraklarda buğday bitkisinin verimini ve bitki gelişimini olumlu etkilediği rapor edilmiştir (Hayman, 1970; Khan, 1975; Thompson, 1990). Mikorizal fungusların en önemli etkileri, bitkinin su ilişkisini düzenlemeleridir. Mikorizanın bitki su ilişkisi üzerine etkisi ile uzun sürede sürdürülebilir tarımda avantaj sağlayabilir (Subramanian vd., 1995).

Mikorizal etkinin; bakır, çinko, demir, kalsiyum, fosfor, magnezyum ve mangan gibi bitki besin elementi alımını arttırdığı ve mikorizal hifler sayesinde toprak içerisinde bulunan besin elementlerinin alımının 60 kat daha fazla olduğu araştırma sonuçlarında ortaya konulmuştur (Bieleski, 1973). Mikorizal funguslar, tuz stresine karşı bitki dayanıklılığını arttırmaktadırlar (Menge vd., 1978). Mikorizal fungusların, azot fiksasyonu yapan Rhizobium bakterilerinin nodül oluşturmasında da olumlu etkiler yaptığı saptanmıştır (Davis, 1978; Davis, 1979; Menge vd., 1980).

Mikorizal fungusların, topraktaki bitkilerce alımı yavaş olan fosforun kontrollü koşullarda bitki tarafından alımını hızlandırdığı yapılan denemelerle gözlenmiştir (Mossea, 1981). Mikorizal funguslar inoküle olmamış bitkilerin kök bölgesinin $1 \mathrm{~cm}$ uzağındaki fosfordan yararlanabilirken, mikorizal funguslarla enfekte olmuş bitki köklerinin fungus hifleriyle kökten 11 $\mathrm{cm}$ uzaktaki fosforu kolaylıkla alabildiği ortaya konulmuştur (Li vd.,1991).

Mikorizal funguslardan Glomus mosseae ve Scutellospora türlerinin domateste bazı büyüme parametrelerine etkileri araştırılmış ve G. mosseae fungus türünün bitki büyümesinin 7 . haftasında bitki boyunu, sürgün kuru madde ağırlığını ve çiçeklenme miktarını kontrol bitkisine göre önemli derecede arttırdığı saptanmıştır (Monther, 2009).

Glomus sp. ve Glomus aggregatum, $G$. clarum, G. deserticola, G. intarardices, G. monosporus, G. mosseae, Gigaspora margaritha, Paraglomus brasilianum içeren mikorizal prepatın domates, hıyar ve biber bitkilerinde fide çıkışı ve gelişimi ile bitki gelişimine olan etkisi üzerine yapılan çalışmada; bitki gelişimi açısından Glomus sp. uygulaması, domates ve hıyar bitkilerinin gelişimlerinde etkili olmuştur. Buna karşılık mikorizal preparatın biber bitkilerinin gelişimi açısından herhangi bir etkisi olmadığı tespit edilmiştir. Ayrıca, bitkilerdeki mikoriza kök kolonizasyon oranının Glomus sp.'de uygulamasında hıyarda $\% 71$, domateste $\% 72$ ve biberde ise $\% 61$ iken mikorizal preparatta daha düşük olduğu tespit edilmiştir (Yıldız, 2009).

Kiraz bitkisinde doku kültürü ile elde edilmiş "Edabariz" ve "Gisela 5" anaçlarının çevre koşullarına uyumlu olma evresinde beslenme ve gelişmeleri üzerine arbüsküler mikorizal fungusların etkisinin araştırıldığı çalışmada, Glomus clarum, G. etunicatum, G. intraradices, G. caledonium ve G. mosseae mikorizal fungus türlerinin karışımı ile mikorizal üç farklı substrat karışımı kullanılmıştır. Mikorizal etki sonucu, tüm anaç bitkiciklerinin şaşırtmada canlılıklarını sürdürerek daha çok besin alımı yaptığı saptanmıştır. Arbüsküler mikorizal fungusların bitkiciklere bulaştırılmasıyla kirazlarda büyüme ve gelişme parametrelerini arttırarak kiraz anacı üretimini iyileştirmede yarar sağlayacakları saptanmıştır (Aka-Kaçar vd., 2010).

Fındık ile ektomikorizal fungus türü olan Lactarius pyrogalus'un farklı izolat ve inokulasyon uygulamasının mikoriza oluşumu ve fidan gelişimi üzerine etkisinin belirlendiği çalışmalarda; L. pyrogalus mantar türünün farklı inokulasyon uygulamaları ve farklı bölgelerden elde edilen izolatların fındık fidanlarında ektomikoriza oluşturduğu ve kontrol uygulamasına göre fidan gelişimlerinde olumlu sonuçlar verdiği tespit edilmiştir (Kibar ve Pekşen, 2011, 2016).

Bitkilerdeki klorofil miktarı üzerine yapılan çalışmada; tohum ekiminden sonra bitkilerin çimlenme, büyüme durumları, bitkilerin yaprak klorofil değerleri ve çiçeklenme zamanları ölçülmüştür. 
Çalışma sonucunda; mikoriza aşılamasının klorofil miktarı üzerine etkili olduğu ve mikoriza aşılaması ile fosfor uygulaması arasında interaksiyon olduğu belirlenmiştir (Akay ve Karaarslan, 2012).

Farklı fosfor dozlarında mikoriza çeşitlerinin tarla koşullarında biberde verim ve bitki gelişimine etkileri üzerine yapılan çalışmada; fosfor uygulamasının tohum aşamasında mikoriza aşılanmış biberde verimi arttırdığı belirlenmiştir. Ayrıca, şaşırtma sırasında yapılan yeniden aşılamanın da verimi artırdığı saptanmıştır (Almaca vd., 2013).

Yetiştirme ortamına ilave edilen mikoriza fungusunun bitki gelişimini, verimini ve meyve kalitesini önemli ölçüde artırdığı belirlenmiş ve verimde kontrol uygulamasına göre \% 42.2 artış sağlanmıştır (Öztekin ve Ece, 2014).

Serada buharla sterilize edilerek, bünyesinde doğal olarak bulunan Arbusküler Mikorizal funguslarının (AMF) azaldığı toprakta yetiştirilen bibere AMF türleri (Glomus caledonium ve $G$. clarum) farklı şekillerde uygulanmıştır. Uygulamaların biberde bitki gelişimi, verim ve bitkinin beslenme durumu üzerine etkileri araştırılmıştır. Çalışma sonucunda; serada AMF ilavesi bitki gelişmesi ve verimi olumlu yönde etkilemiştir. Verim üzerine etkisinde; birer kez uygulamalarda kontrole göre yaklaşık \%16 oranında bir artış, iki kez uygulama da yaklaşık \%29 oranında artış saptanmıştır (Altuntaş vd., 2015).

\subsubsection{Mikorizal Fungusların Bitki Hastalıklarına Karşı Etkinliği \\ Mikorizal fungusların bitki patojenlerinin} etkilerine karşı daha dirençli olduğu fakat mikorizanın patojenlerin neden olduğu hastalığı ortadan kaldırmadığı sadece hastalık simptomları ve şiddetini azalttığı saptanmıştır (Davis, 1978; Davis, 1979; Menge vd., 1980).

Arbusküler Mikorizal (AM) fungusların rizosfer bölgesinin önemli komponentlerinden birisi olması ve bitkiler üzerinde etkili olmaları nedeniyle kök hastalıklarının ve mücadele açısından olumlu etkileri sahiptirler. Çalışmaların büyük bir çoğunluğunda fungal patojenlerin neden olduğu toprak kaynaklı hastalıkların AM fungusları tarafından azaltıldığı çalışmalar sonucunda ortaya konulmuştur (Ocak ve Demir, 2012) (Tablo 1).

Tablo 1. Bazı fungal patojenlere karşı kullanılan Arbusküler Mikorizal Funguslar ve konukçuları (Demir ve Akköprü 2007).

\begin{tabular}{lll}
\hline Fungal Patojen & Konukçu Bitki & Arbusküler Mikorizal Funguslar \\
\hline Aphanomyces euteiches & Bezelye & Glomus intraradices \\
Fusarium oxysporum f.sp. chrysanthemi & Havuç & G. intraradices \\
F.o. f.sp. cucumerinum & Hiyar & G. mosseae \\
F. o. f.sp. radicis-lycopercici & Domates & G. intraradices \\
F. solani & Fasulye & G. mosseae \\
Macrophomina phaseolina & Kavun & G. intraradices \\
Phytophthora fragariae & Çilek & G. fasciculatum \& G. etunicatum \\
P. nicotianae & Domates & G. mosseae \\
P. parastica & Domates & G. intradices Glomus mosseae, \\
& & Gigaspora roseae \\
Pythium ultimum & Soğan & G. intraradices \\
P. ultimum & Biber & G. intraradices \\
Rhizoctonia solani & Fasulye & G. intraradices \\
R. solani & Patates & G. etunicatum, G. intraradices \\
V. dahliae & Patlıcan & G. etunicatium, Gigaspora \\
Verticillium albo-atrum & & margarita G. intraradices \\
\hline
\end{tabular}


Rizosferin ve biyolojik mücadelenin önemli üyeleri olan mikorizal funguslar içinde en çok kullanılan arbusküler mikorizal fungus türlerinden Glomus fasciculatum, G. mosseae ve Rhizobium leguminosarum biovar phaseoli' nin Sclerotinia sclerotiorum ve fasulye bitki gelişimi üzerine etkileri araştırılmıştır. Fasulyede morfolojik değerler dikkate alındığında, patojen populasyonunun uygulamalarda tüm morfolojik değerlerde azaldığı ve bitkilerde toplam azot ve fosfor içeriğinin ise arttığı saptanmıştır (Aysan ve Demir, 2009).

Arbusküler mikorizal funguslar ve bitki patojeni bakteriler arasındaki ilişki ile ilgili çok az sayıda çalışma bulunmaktadır. Arbusküler mikorizal funguslardan en çok kullanılan mikorizal fungus Glomus mosseae' nin domateste Erwinia caratovora' ya karşı bitkilerin direncini arttırdığı ve bakterilerin rizosferde azaldığı saptanmıştır (Garcia-Garrido ve Ocampo, 1988).

Mikorizal funguslardan Glomus mosseae ile aşılanmış domates bitkilerinde fungusun Pseudomonas syringae bakteriyel etmeninin zararını azalttığı saptanmıştır (Garcia-Garrido ve Ocampo, 1989).

Phytophthora parasitica'ya karşı domates köklerinde sistemik dayanıklıığı aktifleştirmek için $G$. mosseae ve $G$. intraradices türlerinin etkinlik oranları karşılaştırılmıştır. G. mosseae türü Phytophthora parasitica'nın domates köklerinde oluşturduğu hastalık belirtilerini azalttığı saptanmıştır. Kök protein ekstraktlarının Phytophthora parasitica'nın hücre duvarında litik etki göstermesi, Phytophthora parasitica'ya karşı mikorizal fungusların sistemik bir etkisinin olduğu saptanmıştır (Pozo vd., 2002).

Domates bitkisiyle G. mosseae fungus hifleri arasındaki misel ağının gelişmesinden sonra bitkilerde, savunma enzimleri olan peroksidase, $\beta-1,3$-glukanase, kitinase, polifenol oksidase, lipoksigenase ve fenilalanin ammonia-liyase aktivitelerinin tetiklenmesiyle bitkinin Phytophthora nicotianae var. parasitica ve Alternaria solani'ye karşı olan dayanıklılık- larında artışlar saptanmıştır. Bu şekilde, sağlam bitkilerin patojen saldırısına karşı kendi savunmalarını aktive ettiği, mikorizal ağ yoluyla da komşu bitkilerdeki savunma sinyallerine karşı etkili olabilecekleri önerilmektedir (Song vd., 2010).

Domateste Fusarium oxysporum f. sp. radicis lycopersici kök ve kök boğazı çürüklüğüne karşı kullanılan organik tarım prepararatları Trichoderma harzianum ve Bacillus subtilis ve bir mikorizal preparat olan $G$. intraradices ile farklı denemeler yapılmıştır. Mikorizal preparat uygulamasının kontrol denemesine nazaran patojenle enfekteli domates bitkilerinde sürgün kuru madde ağırlığı, sürgün boyu ve kök boyunu arttırdığı saptanmıştır. Mikorizal preparat dışında kullanılan $G$. etunicatum'un ise domateslerde bitki gelişimi, verim ve Fusarium oxysporum f. sp. Iycopersici'ye karşı etkili olabildiği belirlenmiştir (Biçici, 2011).

Pamuk bitkisinde G. mosseae mikorizal fungusunun pamukta solgunluğa neden olan Fusarium vasinfectum etmenine karşı hastalık şiddetini azalttığı gözlenmiştir (Hu ve Gui, 1991). G. mosseae, G. versiforme ve Sclerocystis sinuosa mikorizal fungus türleri pamukta Verticillium solgunluk hastalığına karşı kullanılması ile $G$. versiforme bitki patojeninin topraktaki mikrosklerot yoğunluğunu azalttığı belirlenmiştir (Liu, 1995). Tarlada yapılan çalışmalarda ise patıcan bitkisinde Verticillium solgunluğuna karşı $G$. etunicatum ve $G$. margarita mikorizal fungus türlerinin hastalık etkisini belirli oranlarda azalttığı gözlenmiştir (Matsubara vd., 1995).

Mikorizal fungus Glomus etunicatum'un domatesin gelişimini teşvik ederken, bitkide hastalığa karşı dayanıkııık uyarıcı salisilik asit (SA) ile birlikte kullanıldığında G.etunicatum'un domateste solgunluk patojeni Fusarium oxysporum f.sp. lycopersici'nin kökte kolonizasyonunun engellendiğini saptayarak hastalığa karşı mücadelede kullanılabileceğini bildirmişlerdir (Özgönen vd., 2001). 
Hıyar kök çürüklüğü hastalığı Rhizoctonia solani ve Fusarium solani'ye karşı mikorizal fungusların (G. mosseae, G. etunicatum ve G.intraradices) etkinliklerinin belirlendiği sera ve saksı çalışmalarında, bu mikorizal fungusların patojen funguslara doğrudan etkisinin olmadığı görülmüştür. Buna karşılık verim denemelerinde mikorizal fungus uygulamasının kontrole göre verimde artışı sağladığı bildirilmiştir (Yücel vd., 2001).

Arbüsküler mikorizal fungusların, Rhizoctonia, Phytophthora ve Fusarium bitki patojenlerinin neden olduğu hastalıklara karşı alternatif olarak biyolojik mücadelede kullanılabildiği saptanmıştır. Bu çalışmayla arbüsküler mikorizal funguslar ile biyolojik mücadelede kullanılan diğer organizmalar arasında ilişki olduğu saptanmıştır. Bu karşılıklı yararlı etkileşim, bitkilerde kök salgılarını, fitoaleksinleri ve fenolik bileşiklerin üretimini tetiklemektedir. Bu sayede mikorizal funguslar, toprak ve bitki mikrobiyal etkileşimini olumlu şekilde etkilemektedirler. Mikorizal fungal etkinin, bitki savunma genlerinin aktive olmasıyla beraber kitinaz, glukanaz, flavonoid biyosentezi ve fitoaleksinlerin üretimini az da olsa arttırdığı saptanmıştır (Dalpe ve Monreal, 2004).

Mikorizal fungusların salisilik asit (SA) ve DL- $\beta$-amino-nbutyric asit (BABA) ile birlikte kullanıldığında biberlerde kök boğazı yanıklık etmeni Phytophthora capsici'nin infeksiyon potansiyeli üzerine etkilerini araştırmıştır. Mikorizal fungusların tohum ekimiyle birlikte mikorizal inokulum yapılmış olan biber bitkilerinin şaşırtılmasından sonra köklerde $\% 61.3-\% 68.1$ arasında değişen oranlarda kolonize olduklarını belirlemiştir. G. mosseae, $P$. capsici'nin hastalık şiddetini saksı koşullarında $\% 91.7$, sera koşullarında \%43 ve tarla koşullarında ise \%57.2 oranında azaltmıştır (Özgönen, 2004).

Doğu Akdeniz Bölgesi'nde patlıcanda solgunluk hastalığına neden olan Fusarium oxysporum f.sp. melongenae (FOM)'nın yaygınlık oranı ile moleküler karakterizasyonu ve bitkide hastalığa karşı dayanıklııı uyarıcı abiyotik ve biyotik faktörlerin hastalığın gelişimine olan etkisini araştırmıştır. Çalışma sonucunda her iki dayanıklılık uyarıcının da hastalığın önlenmesinde etkin olduğu belirlenmiştir (Altınok, 2006).

Glomus coledonium, G. etunicatum, G. fasciculatus, G. intraradices, G. mosseae, Gigaspora margarita mikorizal fungus türlerinin pamukta bitki gelişim parametreleri ve solgunluk hastalık etmeni olan Verticillium dahliae'nın hastalık şiddeti üzerine etkisinin saptandığı çalışmada; mikorizal fungusların V. dahliae inokulasyonu yapılmadığı ve yapıldığı durumlarda pamuk bitkilerinde kolonizasyon oranlarında artışlar olduğu belirlenmiştir. Önceden mikorizal fungus inokulasyonu yapılmış bitkilerde hastalık şiddeti \%31.3-65.6 azaldığı, hastalık şiddetini azaltmada $G$. mosseae ve $G$. etunicatum' in en etkin türler olduğu saptanmıştır (Özgönen, 2011).

Mikorizal funguslar (Glomus etunicatum, G. fasciculatus, G. mosseae, G. intraradices ve Gigaspora margarita) ve dayanıklılık teşvik edici bazı kimyasalların karpuzda solgunluk etmeni Fusarium oxysporum f.sp. niveum (FON) üzerine etkileri araştırılmıştır. Mikorizal funguslar, FON'un hastalık oluşturmasını \%48.4-58.1 oranında engellemiş ve en etkili mikorizal fungusun $G$. margarita olduğu saptanmıştır (Çınar, 2011).

Geleneksel tarım uygulamalarında; üretim alanlarında uygulanan mücadele ve hatalı tarım uygulamalarının getirdiği birçok olumsuzluk, yetiştiricilikte kullanılacak yöntem ve materyallerin seçimlerinde farklılaşmaya ve alternatif yollar denenmesine imkan sağlamaktadır. Ekosistemin bir parçası olan mikorizal fungusların etkinliği; bitki hastalık ve zararlı organizmalara karşı mücadelede kullanılması, bitki için gerekli bitki besin elementlerinin alım kapasitesini arttırması, bitki gelişimini ve verimi arttırıcı olumlu etkileri bilimsel çalışmalarla ortaya konulmakta ve her geçen gün mikorizal fungusların önemi ve tarımsal üretimde kullanım alanları giderek artmaktadır (Koide ve Mosse, 2004; Almaca, 2014). 


\section{Tartışma}

Bitki kılcal kökleriyle beraber etkileşimde bulunan endomikorizalar ve ektomikorizalar olmak üzere iki önemli mikoriza grubu vardır. Endomikorizalar daha çok Glomeromycota, ektomikorizalar ise Basidiomycota üyesi funguslarca oluşturulur. Mikorizal funguslar, farklı bitki türleri ile etkileşime girerek bitkilerin yararına çeşitli etkiler göstermektedirler. Bu etkiler, bitkinin olumsuz çevre koşullarına karşı bitkiye direnç sağlamak; bitkinin topraktan alamadığı bitki besin elementlerinin alımını sağlamak; bitkinin çeşitli bitki hastalıklarına karşı direncini arttırarak bitkinin dayanıkııı̆ını devam ettirme şeklindedir. Doğada var olan bu ortak yaşam ile bitki ve fungus arasında karşılıklı yararlı bir yaşam oluşmaktadır.

Mikoriza türleri olan ektomikorizaların daha çok orman ağaçları, endomikorizaların ise özellikle arbüsküler mikoriza türü birçok kültür bitkisinde gelişimi, toprak verimliliğini artırdıkları, hastalık ve zararlılara karşı da etkinlik gösterdikleri birçok çalışmada ortaya konulmuştur.

Tarımsal üretimin sürdürülebilirliğinin devam etmesi için tercih edilmesi gereken en etkili ve güvenilir yolun, doğal hayat ekosisteminde yer alan yararlı organizmalarla ilgili yeterli bilgi birikiminin sağlanarak ve bu bilgileri pratiğe aktarılması ve tarım alanlarında alternatif yöntemlerin geliştirilmesi düşünülmektedir. Tarımsal üretimde, bitki beslenmesinde ve bitki koruma amaçlı kullanılan biyolojik mücadele materyallerinin ekosistemde oluşturdukları doğrudan ya da dolaylı etkileşimlerinin detaylı olarak ortaya çıkarılması gerekmektedir. Bu etkiler doğrultusunda özellikle bitki hastalıklarına karşı mücadelede alternatif yollar geliştirilerek bitki hastalıklarının şiddetini azaltmada ve kontrol altında tutmaya yönelik kimyasallara karşı biyolojik mücadelenin gelişmesi, çevre koruması açısından alternatif yöntem olmaktadır. Bu doğrultuda biyolojik mücadelede kullanılan organizmalardan kök sistemleri ile yararlı ortak yaşam oluşturan mikorizal fungusların alternatif biyolojik mücadele elemanı olarak kullanımı yarar sağlayacaktır. Bu derlemede mikorizal fungusların tarımda kullanımıyla ilgili bilgiler verilmesine rağmen, pratik anlamda mikorizal fungusların tarımda, özellikle kültür bitkilerinde etkin kullanımının sağlanabilmesi için zamana intiyaç duyulmaktadır. Yoğun tarım faaliyetlerinin yapıldığı topraklarda özellikle pestisitlerin ve inorganik gübrelerin kullanımının yoğunluğu dikkate alındığında, toprak mikrobiyal potansiyeli, toprak tuzluluğu, ağır metal birikimi vb. toprak kirlilikleri, bu tür bitki kök ve mikorizal etkileşimlerini son derece sınırlandırmaktadır. Dolayısıyla, öncelikle topraklarımızdaki organik madde içeriği, kimyasal ve fiziksel yapısının mikrobiyal faaliyetleri engelleyecek düzeyde olmaması durumunda, mikorizal fungusların tarımda kullanımının önü açılabilecektir. Bunun yanında, Trichoderma harzianum K-12 Rifai strainin oluşturulmasında kullanılan protoplast füzyonu ve benzeri teknolojilerle elde edilecek hibrit mikorizal fungusların, farklı özellikteki topraklara adaptasyonları sağlanarak, tarım alanlarında özellikle örtü altı sebze yetiştiriciliğinde, orman, süs ve meyve fidanı yetiştiriciliğinde etkin kullanımları sağlanabilir.

\section{Kaynaklar}

Aka-Kaçar Y., Akpınar Ç., Agar A., Yalçın-Mendi Y., Serçe S. ve Ortaş I., The effect of mycorrhizas in nutrient uptake and biomass of cherry rootstocks during acclimatization, Romanian Biotechnological Letters, 15 (3): 5246-5250 (2010).

Akay A. ve Karaarslan E., Mikoriza Aşılanmış Kudret Narı (Momordica charantia) Bitkisine Farklı Dozlarda Fosforlu Ve Demirli Gübre Uygulamasının Yaprak Klorofil lçeriğine Etkisi, Iğdır Üniversitesi Fen Bilimleri Enstitüsü Dergisi, 2(3): 103-108 (2012).

Akitsu, N., Hattori, T., Seo, G.S., Ohta, A. and Shimada, M., A possible role of oxalate produced in the symbiotic culture system with a host plant Pinus densiflora and a mycorrhizal fungus Lactarius hatsudake, Wood Research, 87: 13-14 (2000). 
Allen F. M., The ecology of mycorrhizae. Cambridge University Press. pp 184 (1991).

Almaca A., Almaca N. D., Söylemez S. ve Ortaş I., The effects of mycorrhizal species and different doses of phosphorus on pepper (Capsicum annuum L.) yield and development under field conditions, Journal of Food Agriculture and Environment, Vol.11 (3\&4): 647-651 (2013).

Almaca A., Tarımsal Üretimde Mikorizanın Önemi, Harran Tarım ve Gıda Bilimleri Dergisi, 18 (2), 58-67 (2014).

Altınok H. H., Doğu Akdeniz Bölgesi'nde patlıcanda Fusarium solgunluğu hastalığı (Fusarium oxysporum schlecht f.sp. melongenae Matuo and Ishigami)'nın yaygınlığı, etmenin moleküler karakterizasyonu ve bitkide hastalığa karşı dayanıklığın uyarılması, Çukurova Üniversitesi, Fen Bilimleri Enstitüsü, Bitki Koruma Anabilim Dalı, Doktora Tezi, 141 (2006).

Altuntaş Ö., Abak K.ve Daşgan Y. H., Serada biber yetiştiriciliğinde arbusküler mikorhizal fungus kullanımının bitki gelişimi ve verime etkileri, Selçuk Tarım Bilimleri Dergisi, 2(2): 144-151 (2015).

Amaranthus M. P., Mycorrhizal management-A look beneath the surface at plant establishment and growth, http://www.fungi.com (2004).

Anonim (2014). http://www.bioglobal.com.tr

Anonymous (2007). Ectomycorrhizal fungi. http://www.nifg.org.uk/ecto.htm

Aysan E. and Demir S., Using arbuscular mycorrhizal fungi and Rhizobium leguminosarum biovar phaseoli against Sclerotinia sclerotiorum (Lib.) de Bary in the common bean (Phaseolus vulgaris L.), Plant Pathology Journal, 8: 74-78 (2009).

Baylis G. T. S., Effect of vesicular-arbuscular mycorrhizas on growth of Griselinia littoralis (Cornaceae), New Phytologist, 58 (3): 274-278 (1959).

Bieleski R. L., Phosphate pools, phosphate avability, Annual Review of Plant Biology, 24 :225-252 (1973).

Biçici M., Bitki hastalık etmenleri ile biyolojik mücadelenin başarısını arttırmada mikoriza'nın rolü, Türkiye Biyolojik Mücadele Dergisi, 2 (2): 139-174 (2011).

Carlile M. J.and Watkinson S. C., The Fungi. Academic Press, New York, pp 482 (1995).

Çınar Z., Karpuzda fusarıum solgunluğuna (Fusarium oxysporum f.sp. niveum) karşı mikorizal funguslar ve abiyotik uyarıcıların etkilerinin belirlenmesi, Çukurova Üniversitesi, Fen Bilimleri Enstitüsü Yüksek Lisans Tezi, Adana, s. 70 (2011).

Dalpe Y. and Monreal M., Arbuscular mycorrhiza inoculum to support sustainable cropping systems, Online. Crop Management, (2004).

Davies F. T. Jr., Potter J. R. and Linderman R. G., Mycorrhiza and repeated drought exposure affect drought resistance and extra radical hyphae development of paper plants independent of plant size and nutrient content, Journal Plant Physiology, 139: 289-294 (1992).

Davis R. M., Influence of vesicular-arbuscular mycorrhizae on Phytophthora root rot of three-crop plant, Phytopathology, 68: 1614-1617 (1978).

Davis R. M., Influence of Glomus fasciculatus and soil phosphorus on Verticillium wilt of cotton, Phytopathology, 69: 453-456 (1979).

Dehne, H.W. and Schanbeck F., Untersuchungen zum einfluss der endotrophen mykorrhiza auf pflanzenkrankheiten, II. Phenolstoffwechsel und Lignifizierung, Phytopathology, 95: 210-216 (1979).

Demir S. ve Onoğur E., Bitkilerde vesiküler-arbüsküler mikoriza oluşumunun bitki besleme ve bitki korumadaki önemi, Anadolu Dergisi, 9(2): 12-32 (1999).

Demir S.ve Akköprü A., Using of Arbuscular Mycorrhizal Fungi (AMF) for biocontrol of soil-borne fungal plant pathogens, In: Biological Control of Plant Diseases Chincholkar SB and Mukerji KG (eds), Haworth Press, NY, USA, pp. 17-37 (2007).

Erzurumlu G. S. ve Kara E. E., Mikoriza konusunda Türkiye'de yapılan çalışmalar, Türk Bilimsel Derlemeler Dergisi, 7 (2): 55-65 (2014). 
FrankA.B., Über die auf wurzelsymbiose beruhende ernährung gewisser baume durch unterirdische pilze, Berichte der Deutsche Botanische Gesellschaft, 3: 128-145 (1885).

Gai J. P., Christie P., Feng G. and Li X. L., Twenty years of research on community composition and species distribution of arbuscular mycorrhizal fungi in China, Mycorrhiza, 16: 229-239 (2006).

Garcia-Garrido J. M. and Ocampo J. A., Interaction between Glomus mosseae and Erwinia carotovora and its effects on the growth of tomato plants, New Phytologist, 110 (4): 551-555 (1988).

Garcia-Garrido J. M. and Ocampo J. A., Effect of VA mycorrhizal infection of tomato on damage caused by Pseudomonas syringae, Soil Biology and Biochemistry, 21 (1): 165-167 (1989).

Graham J. H., Leonard R.T. and Menge J.A., Membrane-mediated decrase in root exudation responsible for phosphorus inhibition of vesicular-arbuscular mycorrhiza formation, Plant Physiology, 68: 548$552(1981)$.

Harley J. L. and Smith S. E., Mycorrhizal symbiosis. Academic Press.London, pp 63 (1983).

Hayman D.S., Endogone spore number in soil and WAM in wheat as influenced by season and soil treatment. Transactions of the British Mycological Society, 54: 219-226 (1970).

Hayman D., Mycorhiza and it's significance in horticulture, The Plantsman, 2(4): 214-224 (1981).

Holt J. R., Systematic biology-fungi. Course syllabus, Susquehanna University, Pennsylvania, USA (2009).

Hu Z. J. and Gui X. D., Pretransplant inoculation with VA mycorrhizal fungi and fusarium blight of cotton, Soil Biology and Biochemistry, 23: 201-203 (1991).

Isaac S., Fungal Plant Interactions, Chapman and Hall, London, UK, pp 418 (1992).

Kara Ö., Mikoriza ve orman ağaçları için önemi, I. Ulusal Orman Fakülteleri Öğrenci Kongresi Bildirileri, 4-5 Mayıs, s. 199-205, İstanbul (2000).

Kara Ö. ve Tilki F., Mikoriza ve ormancılıkta kullanımı, I.Ü. Orman Fakültesi Dergisi, 51(1): 127-139 (2001).

Khan A. G., Growth effect of VA mycorrhiza on crops in the field in Endomycorrhizas, London, pp 419-435 (1975).

Kibar B. ve Pekşen A., Ektomikorizanın tarım ve ormancılık bakımından önemi, Ondokuz Mayıs Üniversitesi Ziraat Fakültesi Dergisi 22 (2): 232-238 (2007).

Kibar B. ve Pekşen A., Lactarius pyrogalus mantar türünün farklı izolatlarının ve inokulasyon uygulamalarının fındık (Corylus avellana) fidanında ektomikoriza oluşumu ve fidan gelişimi üzerine etkisi, Düzce Üniversitesi Ormancılık Dergisi, 7(2): 89-104 (2011).

Kibar B. ve Pekşen A., Lactarius pyrogalus'un değişik inokulum uygulamalarının fındıkta (Corylus avellana) bitkigelişimi üzerine etkileri, Anadolu Tarım Bilimleri Dergisi, 31 (2016) 191-198 (2016).

Koide R.T. and Mosse B., A history of research on arbuscular mycorrhiza, Mycorrhiza, 14: 145-163 (2004).

Li X. L., Marschner H. and George E., Acquisition of phosphorus and copper in VA-mycorrhizal hyphae and root-to-shoot transport in white clover, Plant and Soil, 135: $49-57$ (1991).

Liu, R.J., Effect of vesicular-arbuscular mycorrhizal fungi on Verticillium wilt of cotton. Mycorrhizae, 5(4): 293-297 (1995).

Matsubara Y., Tamura, H. and Harada, T., Growth enhancement and Verticillium wilt control by vesiculararbuscular mycorrhizal fungus inoculation in eggplant, Journal of the Japanese Society for Horticultural Science, 64(3): 555-561 (1995).

Marschner H., Mycorrhizas. mineral nutrition of higher plants, Academic Press, pp 566-595 (1995).

Martin F. and Slater H., An evolving host for mycorrhizal research, New Phytologist, 174(2):225-228 (2007).

Marx D. H., Forest application of the ectomycorrhizal fungus Pisolithus tinctorius, The Prize, Ectomycorrhizal fungi, Lecture: Part I of II (2001). 
Menge J. A., Labanauskas C. K., Jonhson E. L. V. and Platt R. G., Partical substitution of mycorrhizal fungi for phosphorus fertilization in the greenhouse culture of citrus, Soil Science Society of America Journal, 42: 926 -930 (1978).

Menge J. A., Jarrel W., Labanauskas, W. M., Ojala J. C., Huszar C. E., Johnson L. V. and Sibert D., Predicting mycorrhizal dependency of troyer citrange on Glomus fasciculatus in California citrus soils, Soil Science Society of America Journal, pp 43 (1980).

Molina R., O'Dell T., Luoma D., Amaranthus M., Castellano M. and Russel K., Biology, ecology and social aspects of wild edible mushrooms in the forests of the Pacific Northwest: a preface to managing commercial harvest, General Technical Report, Portland, pp 42 (1993).

Molina R., Pilz D., Smith J., Dunham S., Dreisbach T., O'Dell T. and Castellano M., Conservation and management of forest fungi in the Pacific Northwestern United States: an integrated ecosystem approach, Cambridge University Press, pp. 10-63 (2001).

Monther M. T., Mechanisms involved in the biological control of tomato bacterial wilt caused by Ralstonia solanacearum using arbuscular mycorrhizal fungi, Universiti Putra, Malaysia (2009).

Moser M. and Haselwandter K., Ecophysiology of mycorrhizal symbiosis, Encylopedia of Plant Physiology, 12: 391-421 (1975).

Mossea B., Vesicular-arbuscular mycorrhiza research for tropical agriculture. Research Bulletin. Hawaii Institute of Tropical Agriculture and Human Resources, pp 82 (1981).

Mycorrhizal associations. David Moore's World of Fungi: Where mycology starts. http://mycorrhizas.info (2008).

Ocak E. ve Demir S., Toprak verimliliği ve bitki gelişiminde peyniraltı suyu ve Arbusküler Mikorhizal Fungus (AMF)'un önemi, YYÜ Tarım Bilimleri Dergisi (YYU J AGR SCI), 22(1): 48-55 (2012).

Ortaş (1998). http://www.ekizfidancilik.com

Ortaş, I., Do plants depend on mycorrhizae in terms of nutrient requirement international conference on sustainable land use and management, Çanakkale (2002).

Özgönen, H., Biçici, M. and Erkılıç, A., The effect of salicyclic acid and endomycorrhizal fungus Glomus etunicatum on plant development of tomatoes Fusarium wilt caused by Fusarium oxysporum f.sp. lycorpersici, Turkish Journal of Agriculture and Forestry, 25:25-29 (2001).

Özgönen, H., Biberde kökboğazı yanıklığı (Phytophthora capsici Lenion)'na karşı mikorizal funguslar, salisilik asit ve DL- $\beta$-amino-Nbutirik asit ile dayanıkııı̆ın teşvik edilmesi, Çukurova Üniversitesi, Fen Bilimleri Enstitüsü, Bitki Koruma Anabilim Dalı, Doktora Tezi, s. 122 (2004).

Özgönen H., Armüsküler mikorizal fungusların pamukta bitki gelişimine ve Verticillium Solgunluğu(Verticillium dahliae Kleb.) Üzerine etkileri, Süleyman Demirel Üniversitesi, Fen Bilimleri Enstitüsü Dergisi, 15 (3):171-177 (2011).

Öztekin G. B. ve Ece M., Sera domates yetiştiriciliğinde Symbion AM (Glomus fasciculatum) inokulasyonunun bitki gelişimi, verim ve meyve kalitesi üzerine etkisinin belirlenmesi, Türkiye Tarımsal Araştırmalar Dergisi, 1(1): 35-42 (2014).

Pekşen A. ve Kibar B., Yenilebilir ektomikorizal mantarların yetiştiriciliği ve bu konuda yapılan çalışmalar, Ondokuz Mayıs Üniversitesi Ziraat Fakültesi Dergisi, 22 (2): 239- 247 (2007).

Peterson R.L. and Farquhar M.L., Mycorrhizas-Integrated development between root and fungi, Mycologia, 86 (3): 311-326 (1994).

Peterson R.L., Massicotte H.B. and Melville L.H., Anatomy and Cell Biology. Mycorrhizas, National Research Council of Canada, Ottawa, Ontario, pp: 173 (2004).

Plantscience4u, (2016). http://www.plantscience4u.com.

Pozo M. J., Cordier C., Dumas-Gaudot E., Gianinazzi S., Barea J. M. and Azcon-Aguilar C., Localized versus systemic effect of arbuscular mycorrhizal fungi on defense responses to Phytophthora infection in tomato plants, Journal of Experimental Botany, 53 (368): 525-534 (2002). 
Redecker D., Glomeromycota. arbuscular mycorrhizal fungi and their relative (s), The Tree of Life Web Project, (2008).

Repac, I., Ectomycorrhiza formation and growth of Picea abies seedlings inoculated with alginate-bead fungal inoculum in peat and bark compost substrates, Forestry, 80(5): 517-530 (2007).

Robson A., Abbott L. K. and Schweiger P. F., Benefits of VA mycorrhizas in agricultural and horticultural production, 9th North American Conference on Mycorrhizae Guelph, Ontario, Canada, 51: 231239 (1993).

Sharma A. K., Johri B. N. and Gianinazzi S., Vesicular-arbuscular mycorrhizae in relation to plant disease. World Journal of Microbiology and Biotechnology, 8 (6): 559-563 (1992).

Sieverding E., Vesicular-arbuscular mycorrhizae management in tropical agrosystems, Technical Cooperation, Federal Rebpublic of Germany pp 372 (1991).

Smith S. E. and Read J. D., Mycorrhizal symbiosis, (Ed) by A D. Robson. Kluwer Academic Publishers. London, pp 36 (1997).

Smith S. E. and Read D. J., Mycorrhizal symbiosis, 3th Ed., Academic Press, pp 800 (2008).

Song Y. Y., Zeng R. S., XU J. F., Li J., Shen X. and Yihdego W. G., Interplant communication of tomato plants through underground common mycorrhizal networks, PLoS One. 13; 5(10): 13324 (2010).

Souza, L.A.B., Filho, G.N.S., Oliveira, V.L., Efficiency of ectomycorrhizal fungi on phosporus uptake and eucalypt growth promotion, Pesquisa Agropecuaria Brasileira, 39(4): 349-355 (2004).

Subramanian K. S., Charest C., Dwyer L. M., and Hamilton R. I., Arbuscular mycorrhizal and water relations in maize under drought stress at tasseling, New Phytologist, 129: 643-650 (1995).

Thompson J. P., Soil sterilization methods to show VA-Mycorrhizae aid $P$ and $Z n$ nutrition of wheat in vertisols, Soil Biology and Biochemistry 22 (2): 229-240 (1990).

Tilki F. ve Kara Ö., Silvikültürel müdahalelerin ektomikoriza mantarları üzerine etkisi, Gazi Üniversitesi Orman Fakültesi Dergisi, 4(1): 81-90 (2004).

Toprak B., Yıldız O., Altundağ E., Güner T., Sargıncı M., Pekşen A. ve Mutlu, Ö., Ektomikoriza ve endomikoriza aşılamasının toros sediri (Cedrus libani), karaçam (Pinus nigra) ve saçlı meşe (Quercus cerris) fidanlarının büyümeleri üzerine etkileri, Doğu Akdeniz Üniversitesi Eczacılık Fakültesi Ekoloji 2014 Sempozyumu Bildiri Özetleri Kitabı, (1-4 Mayıs 2014), s. 51, Gazimağusa, Kıbrıs (2014).

Toprak B., Yıldız O., Sargıncı M., Güner Ş.T., Pekşen A., Çakır E. A., Mikoriza Uygulamasının Karaçam (Pinus nigra) Fidanlarının Morfolojik Özelliklerine Etkisi, Ormancılık Dergisi, 12(2): 258-269 (2016).

Turjaman, M., Tamai, Y., Segah, H., Limin, S.H., Osaki, M., Tawaray, K., Increase in early growth and nutrient uptake of Shorea seminis seedlings inoculated with two ectomycorrhizal fungi, Journal of Tropical Forest Science, 18(4): 243-249 (2006).

Tüfekçi S., Doğal Populasyonlardaki Toros Sediri (Cedrus libani A. Rich.) Mikorizasının İzole Edilmesi ve Çoğaltııp Fidan Üretiminde Kullanılması, Doktora Tezi, Çukurova Üniversitesi Fen Bilimleri Enstitüsü, 179s, Adana (2007).

Yıldız, A., A native Glomus sp. from fields in Aydın province and effects of native and commercial mycorrhizal fungi inoculants on the growth of some vegetables, Turkish Journal of Biology, 34(4): 447-452 (2009).

Yücel, S., Elekçioğlu, H., Özgönen, H., Toktay, H. ve Ortaş, I., Seralarda fungal kök hastalıklarına ve kökur nematodlarına karşı solarizasyon ve mikorizal fungus kombinasyonlarının etkilerinin araştırılması, Türkiye IX. Fitopatoloji Kongresi. 3-8 Eylül, Tekirdağ, s. 421-431(2001). 